\title{
Endoscopic treatment of ureterovesical junction obstructive pathology: A description of the oblique meatotomy technique and results
}

\author{
Miguel Arrabal-Martín, MD, PhD; Armando Zuluaga-Gómez, MD, PhD; Sergio Merino-Salas, MD; \\ Mercedes Nogueras-Ocaña, MD, PhD; Miguel Ángel Arrabal-Polo, MD, PhD
}

Urology Department, San Cecilio University Hospital, Granada, Spain

Cite as: Can Urol Assoc J 2013;7(11-12):e728-31. http://dx.doi.org/10.5489/cuaj.496 Published online November 8, 2013.

\section{Abstract}

Background: Benign obstructive pathology of the ureterovesical junction includes congenital and acquired illnesses. The objective of this study was to describe the endoscopic oblique meatotomy technique using scissors and cold cutting to treat benign obstructive pathology of the ureterovesical junction.

Methods: From 2007 to 2012, we treated 18 patients with obstructive pathology of the ureterovesical junction ( 5 megaureters [ 3 with lithiasis], 4 iatrogenic stenoses, and 9 ureteroceles with lithiasis). In all cases, oblique meatotomy was performed using endoscopic scissors through an $8.5 \mathrm{Ch}$ ureteroscope. The mean follow-up for all patients was 3 years. Pain, grade of hydronephrosis, and occurrence of vesicoureteral reflux were evaluated before and after treatment.

Results: The mean endoscopic treatment time was 13.4 minutes. The procedure was performed on an outpatient basis with 6 hours of hospital admission, and a double J stent was inserted for 6 weeks. We achieved treatment success in $94.5 \%$ of patients after 3 years of follow-up. Only 1 patient presented with vesicoureteral reflux at 12 months after treatment; however, this condition did not require further treatment. Overall, $100 \%$ of patients remained free from lithiasis. There are 2 main limitations: the small number of patients and the lack of another group to compare the results of this technique; however, the aim of this work was to communicate a new technique to treat ureterovesical junction stricture

Interpretation: Oblique ureteral meatotomy is a safe and effective treatment for benign obstructive pathology of the ureterovesical junction and has a low index of complications.

\section{Introduction}

At the ureterovesical junction, 3 ureteral segments are distinguished: the juxtavesical, intramural, and submucosal segments. These segments are associated with the
Waldeyer's Sheath and the prevesical sphincter described by S. Gil Vernet. ${ }^{1,2}$ Congenital alterations (megaureters and ureteroceles) or acquired alterations can give rise to urinary obstruction or vesicoureteral reflux. As a treatment for urinary obstruction, endoscopic ureteral meatotomy can produce vesicoureteral reflux..$^{1,2}$

Protection against vesicoureteral reflux is provided by the submucosal ureteral tunnel next to the Waldeyer's muscular sheath and by the circular muscular fibres of the prevesical sphincter at the distal ureter. ${ }^{1-3}$

Classically, the treatment of obstructive pathology of the ureterovesical junction due to congenital or acquired causes has involved open surgery, ureteral reimplantation, or nephrectomy in cases of renal function loss. ${ }^{4,5}$ However, the development and progression of technological improvements in endoscopic techniques and instruments have made this approach a valid option for the initial treatment of obstructive ureterovesical pathology that produces good results. ${ }^{6-8}$

Endoscopic treatment of obstructive ureterovesical pathology using meatotomy in an oblique direction can preserve the submucosal tunnel and the muscular sheath and conserve the valvular function of the submucosal ureter or medial valve, thus preventing the occurrence of vesicoureteral reflux.

The objective of this study was to describe the surgical technique and the results of oblique ureteral meatotomy.

\section{Methods}

Over a 5-year period (April 2007 to March 2012), a prospective study was conducted to analyze the results of oblique ureteral meatotomy that was performed using endoscopic scissors. All of the patients received information about the study and signed informed consent forms.

We included 18 consecutive cases of stenosis of the ureterovesical junction in 11 women and in 7 men between 
the ages of 26 and 60 years $(41.6 \pm 15.7): 5$ cases of an obstructive megaureter without reflux ( 3 cases with ureteral lithiasis), 4 cases of stenosis of the ureteral meatus secondary to endoscopic bladder surgery, and 9 cases of an orthotopic ureterocele with lithiasis.

The inclusion criterion was benign, intrinsic stenosis of the ureterovesical junction. The exclusion criteria were extrinsic stenosis or malignant intrinsic stenosis of the ureterovesical junction. No patients had previous treatment to meatotomy and none had a nephrostomy tube or ureteral stent. In all 18 cases, a diagnosis was based on intravenous urography and endoscopic exploration using a diuretic renogram with MAG3 and cystography in the 5 megaureter cases.

The procedure was performed under analgesia and sedation in an outpatient setting with a mean hospital stay of 6 hours. We used a semi-rigid, 8.5 Ch Olympus ureteroscope (Olympus, Center Valley, PA) with 2 working channels; endoscopic scissors (size $5 \mathrm{Fr}$ and $60-\mathrm{cm}$ long); and Dornier Medilas 20-watt laser equipment for the fragmentation of lithiasis or for hemostasis. Ureterocystoscopy, trigonal, and bladder exploration were performed with the patient in the lithotomy position. The ureteral orifice was identified, and a number $3 \mathrm{Fr}$ catheter or flexible guide wire that was 6 to $8 \mathrm{~mm}$ in length was inserted into an oblique section of the ureteral meatus and into the intravesical submucosal ureteral tract. In the right ureter, the incision was performed by dividing from the point that corresponded to the 5 o'clock position of the ureteral meatus in a medial and posterior direction (Fig. 1, part A). In the left ureter, the incision was begun at the $7 \mathrm{o}^{\prime}$ clock position in a medial and posterior direction (Figure 1, part B). The incision was performed using endoscopic scissors and cold cutting. In 3 cases, the incision was performed with hemostasis of the sectioned ureterovesical wall using a Holmium-YAG laser. Then, ureteral exploration and/or treatment of ureteral lithiasis was performed (lasertripsy and/or extraction of the calculus with a nitinol basket in 12 cases). At the end of the procedure, a ureteral double J stent was placed for 6 weeks.

A prophylactic antibiotic theraphy was performed with cefuroxime axetil $1500 \mathrm{mg}$ endovenous, and antibiotic treatment 5 days with oral cefuroxime axetil 500 mg every 12 hours.

We evaluated the grades of hydronephrosis and pain before and after treatment. The first evaluation of the results was performed at 3 months with urography and an analysis of postoperative complications. Cystography was performed at 12 months, and urography and a clinical evaluation was performed at 24 and 36 months. Therapeutic success was defined as the absence of pain, the absence of urinary tract dilation or a decrease in the hydronephrosis grade, and the absence of vesicoureteral reflux. In all cases, 3 years of follow-up was conducted.

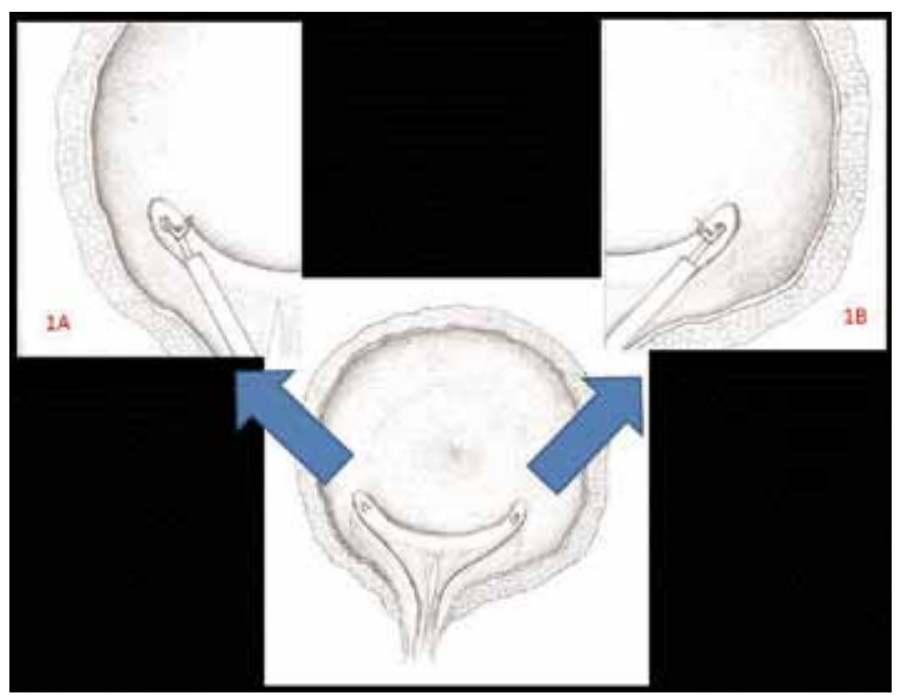

Fig. 1. In figure 1a we can see the ureteroscopy and endoscopic scissors in right meatus performing the meatotomy at 5 o'clock. In figure $1 \mathrm{~b}$, the ureteroscopy and endoscopic scissors are placed in left meatus to perform the meatotomy at 7 o'clock.

\section{Results}

A total of 18 patients presented with unilateral obstructive pathology of the ureterovesical junction due to a stricture lower than $8 \mathrm{~mm}$ (Table 1 ). The mean procedure time was $13.4 \pm 3.2$ minutes. Only 1 patient with a ureterocele required hospital admission for 72 hours due to hematuria, which ceased with conservative measures. In the remaining patients, the procedure was performed on an outpatient basis after a 6-hour hospital stay for observation. At 3 months, a decrease in pain and a decrease in the grade of hydronephrosis or the disappearance of this condition were observed in the patients. In addition, $100 \%$ of the cases of associated lithiasis in 12 patients (Table 1) were resolved. No patient presented with fever or a urinary tract infection at 3 months. In the only megaureter case, an increase in the grade of hydronephrosis and in pain occurred at 24 months after endoscopic treatment. In this patient with megaureter, the first meatotomy failed but no renal damage in renogram was observed, and a re-treatment with oblique meatotomy was performed; 6 months later the patient was asymptomatic and with the same grade of hydronephrosis. After performing cystography at 12 months, we observed vesicoureteral reflux in only 1 patient (5.5\%). The treatment was effective in 4 of the 5 cases of megaureter, 9 cases of orthotopic ureterocele, and 4 cases of iatrogenic stenosis of the ureteral meatus. Overall, the success rate at 36 months was $94.5 \%$.

\section{Discussion}

Different studies have indicated that an endoscopic incision can obtain good results for obstructive megaureters 


\begin{tabular}{|c|c|c|c|c|c|c|c|c|c|}
\hline \multicolumn{5}{|c|}{ Parameters previous treatment with endoscopic scissors } & \multicolumn{5}{|c|}{ Results after treatment } \\
\hline \multirow[t]{2}{*}{ Causes } & \multirow[t]{2}{*}{$\begin{array}{l}\text { No. } \\
\text { cases }\end{array}$} & \multirow[t]{2}{*}{ Pain } & \multirow[t]{2}{*}{$\begin{array}{l}\text { Lithiasis } \\
\text { associated }\end{array}$} & \multirow[t]{2}{*}{$\begin{array}{c}\text { Urography } \\
\text { (hydronephrosis) }\end{array}$} & \multirow[t]{2}{*}{$\begin{array}{l}\text { Pain at } 3 \\
\text { months }\end{array}$} & \multirow[t]{2}{*}{$\begin{array}{l}\text { Pain at } \\
24-36 \\
\text { months }\end{array}$} & \multicolumn{2}{|c|}{$\begin{array}{c}\text { Urography } \\
\text { (hydronephrosis, } \\
\text { no. patients) }\end{array}$} & \multirow[t]{2}{*}{$\begin{array}{c}\text { Cistography } \\
\text { at } 12 \text { months, } \\
\text { VUR }\end{array}$} \\
\hline & & & & & & & 3 months & $\begin{array}{c}24-36 \\
\text { months }\end{array}$ & \\
\hline Megaureter & 5 & $\begin{array}{l}\text { Moderate: } 3 \\
\text { Mild: } 2\end{array}$ & 3 & $\begin{array}{l}\text { Degree II: } 2 \\
\text { Degree III: } 3\end{array}$ & No pain: 5 & $\begin{array}{l}\text { No pain: } 4 \\
\text { Mild: } 1\end{array}$ & $\begin{array}{l}\text { Degree I: } 3 \\
\text { Degree II: } 2\end{array}$ & $\begin{array}{l}\text { Degree I: } 3 \\
\text { Degree II: } 1 \\
\text { Degree III: } 1\end{array}$ & $\begin{array}{l}\text { Degree I: } 1 \\
\text { No VUR: } 4\end{array}$ \\
\hline Ureterocele & 9 & $\begin{array}{l}\text { Moderate: } 5 \\
\text { Mild: } 4\end{array}$ & 9 & $\begin{array}{l}\text { Degree I: } 8 \\
\text { Degree II: } 1\end{array}$ & No pain: 9 & No pain: 9 & No pain: 9 & No pain: 9 & No pain: 9 \\
\hline Meatus stenosis & 4 & Severe: 4 & 0 & Degree III: 4 & No pain: 4 & No pain: 4 & No pain: 4 & No pain: 4 & No pain: 4 \\
\hline
\end{tabular}

in $70 \%$ to $80 \%$ of cases with a low index of vesicoureteral reflux occurrence. When reflux is present after endoscopic treatment, this condition is typically low grade and disappears within months in most patients. ${ }^{8-11}$ The endoscopic incision is typically performed at the $6 \mathrm{o}^{\prime}$ clock or at 6 and $12 \mathrm{o}^{\prime}$ clock positions; ${ }^{8,10}$ however, we performed the incision at the $5 \mathrm{o}^{\prime}$ clock position in the right ureter and at the 7 o'clock position in the left ureter. The occurrence of reflux at 12 months after treatment in a patient who presented with an obstructive megaureter was similar to the findings in the literature and did not have any clinical impact. ${ }^{10-13}$

In our study, the 4 cases of stenosis of the ureteral meatus that we treated were secondary, similar Strup and colleagues' results ${ }^{12}$ on the endoscopic treatment of bladder pathology. In their study, 7 patients were treated with a transureteral and percutaneous approach using an incision with scissors or a ureterotome. Treatment success was achieved in 6 patients without clinical evidence of vesicoureteral reflux. In our study, we achieved treatment success in $100 \%$ of the patients without evidence of vesicoureteral reflux 12 months after treatment.

The third type of obstructive pathology that we treated was a ureterocele in 9 cases, and all of these cases were accompanied by lithiasis. Shah and colleagues treated a total of 13 patients who presented with a ureterocele, 2 of whom had a bilateral ureterocele, using an endoscopic incision with a Holmium-YAG laser. Follow-up was performed for 11 patients, and the success rate was $100 \%$. Vesicoureteral reflux was present in 4 patients at 3 months, but had disappeared by 6 months. ${ }^{13}$ Isen treated 5 women who presented with an orthotopic ureterocele using an incision with scissors, which resulted in a $100 \%$ success rate and the clinical absence of vesicoureteral reflux. ${ }^{14}$ Moreover, Spatafora and colleagues performed a combined transurethral and percutaneous transvesical treatment using a Collins knife incision in 15 adult patients who presented with a ureterocele. The treatment was successful in all of the patients, with 2 cases of vesicoureteral reflux that did not require additional treatment. ${ }^{15}$ The initial endoscopic treatment of orthotopic ure- teroceles was more successful than the treatment of ectopic ureteroceles, as it produced a better decompression of the ureter..$^{16}$ In our study, we treated 9 patients who presented with an orthotopic ureterocele and lithiasis. Treatment success and resolution of lithiasis were achieved in $100 \%$ of these cases. We did not observe vesicoureteral reflux 12 months after treatment. Our results were similar to other studies, yet they indicate a lower index of vesicoureteral reflux. We think that oblique meatotomy can preserve the submucosal tunnel and the muscular sheath better than other technique of meatotomy (although this point should be confirmed with a clinical trial comparing oblique meatotomy with other techniques of meatotomy). It is possible that oblique meatotomy conserves the valvular function of the submucosal ureter or medial valve, due to the cut of stricture is performed in parallel to the fibres. However, this point should be confirmed with histology studies in experimental studies.

Endoscopic incision of the ureteral meatus can be performed using a laser, electric cutting, or cold cutting. We opted to use cold cutting with endoscopic scissors because this technique enables greater control and visibility of the incision than a laser or with electric cutting. ${ }^{17}$ Moreover, the scarring process after cold cutting produces less fibrosis than monopolar electric cutting, ${ }^{18}$ thus improving the long-term results. In our study, oblique meatotomy performed with cold cutting using endoscopic scissors demonstrated a success rate of $94.5 \%$ at 36 months, with a low index of overall vesicoureteral reflux and its associated complications.

Additional comparative and prospective studies are needed using other endoscopic and surgical treatment methods to definitively establish oblique meatotomy as a first-line treatment in benign obstructive pathology of the ureterovesical junction.

\section{Conclusion}

This study provides the description of an incision technique with good results and a high success rate over a long follow- 
up period. Oblique ureteral meatotomy performed with cold cutting using endoscopic scissors has been demonstrated to be useful to treat obstructive pathology of the ureterovesical junction (obstructive megaureter, ureterocele, and stenosis of the ureteral meatus) with a high success rate and a low index of complications. Therefore, this technique may be used as a first-line treatment in selected patients without retrospectively excluding any other type of treatment.

Acknowledgements: The authors thank Verónica Quiros Ruz for the details on Figure 1.

Competing interests: Dr. Arrabal-Martín, Dr. Zuluaga-Gómez, Dr. Merino-Salas, Dr. Nogueras-Ocaña and Dr. Arrabal-Polo all declare no competing financial or personal interests.

This paper has been peer-reviewed.

\section{References}

1. Churchill BM, Abara E0, McLorie GA. Ureteral duplication, ectopy and ureteroceles. Pediatr Clin North Am 1987;34:1273-89.

2. Tanagho EA. Embryologic basis of lower ureteral abnormalities: a hypothesis. Urology 1976;7:451. http://dx.doi.org/10.1016/0090-4295(76)90179-5

3. Tanagho EA. Anatomy and management of ureteroceles. J Urol 1972;107:729-36.

4. Beganovic $A$, Klijn AJ, Dik P, et al. Ectopic ureterocele: long-term results of open surgical therapy in 54 patients. J Urol 2007;178:251-54. http://dx.doi.org/10.1016/i.juro.2007.03.063

5. De Jong TP, Dik P, Klijn AJ, et al. Ectopic Ureterocele: results of open surgical therapy in 40 patients. J Urol 2000;164:2040-3. http://dx.doi.org/10.1016/S0022-5347(05)66961-3

6. Adorisio 0 , Elia $\mathrm{A}$, Landi $\mathrm{L}$, et al. Effectiveness of primary endoscopic incision in treatment of ectopic ureterocele associated with duplex system. Urology 2011;77:191-4. http://dx.doi.org/10.1016/i. urology.2010.02.061
7. Vijay MK, Vijay P, Dutta A, et al. The safety and efficacy of endoscopic incision of orthotopic Ureterocele in adult. Saudi J Kidney Dis Transpl 2011;22:1169-74.

8. Christman MS, Kasturi S, Lambert SM, et al. Endoscopic management and the role of double stenting for primary obstructive megaureters. J Urol 2012;187:1018-23. http://dx.doi.org/10.1016/i. juro.2011.10.168

9. Angulo JM, Arteaga R, Rodríguez Alarcón J, et al. Role of retrograde endoscopic dilatation with balloon and derivation using double pig-tail catheter as an initial treatment for vesico-ureteral junction stenosis in children. Cir Pediatr 1998;11:15-8.

10. Bapat $S$, Bapat $M$, Kirpekar $D$. Endoureterotomy for congenital primary obstructive megaureter: preliminary report. J Endourol 2000;14:263-7. http://dx.doi.org/10.1089/end.2000.14.263

11. Biyani CS, Powell CS. Congenital megaureter in adults: endoscopic management with holmium:YAG laser-preliminary experience. J Endourol 2001;15:797-9. http://dx.doi. org/10.1089/089277901753205771

12. Strup SE, Bagley DH. Endoscopic ureteroneocystostomy for complete obstruction at the ureterovesical junction. J Urol 1996;156:360-2. http://dx.doi.org/10.1016/S0022-5347(01)65850-6

13. Shah N, Sodha H, Khandkar AA, et al. Endoscopic management of adult orthotopic ureterocele and associated calculi with holmium laser: experience with 16 patients over 4 years and review of literature. J Endourol 2008;22:489-96. http://dx.doi.org/10.1089/end.2007.0312

14. Isen K. Technique using a percutaneous nephroscope and nephroscopic scissors transurethrally for treatment of complicated orthotopic ureterocele in adult women. Urology 2012;79:713-6. http://dx.doi. org/10.1016/i.urology.2011.11.046

15. Spatafora $S$, Buli P, Leoni $S$. Combined percutaneous-transurethral incision for treatment of Ureterocele in adults. Urology 2006;68:1333-5. http://dx.doi.org/10.1016/i.urology.2006.09.010

16. Byun E, Merguerian PA. A meta-analysis of surgical practice patterns in the endoscopic management of ureteroceles. J Urol 2006;176:1871-7. http://dx.doi.org/10.1016/S0022-5347(06)00601-X

17. Arrabal Martín M, Jiménez Pacheco A, Arrabal Polo MA, et al. Cold cutting of ureteral stenosis with endoscopic scissors. Urology 2009;74:422-6. http://dx.doi.org/10.1016/i.urology.2008.11.027

18. Soria Gálvez F, Morcillo Martín E, Martín García C, et al. Valoración de la eficacia de la endoureterotomía con tijeras frente a la endoureterotomía monopolar en el tratamiento de estenosis ureterales en modelo animal. LXXVI National Congress of Urology of Spanish Urological Association. Malaga. Spain. 2011.

Correspondence: Dr. Miguel Angel Arrabal-Polo, Camino de Ronda street, 143, 4F. Granada. Spain 18003; arrabalp29@gmail.com 